\title{
Prática do Futsal na Escola: Motivação de Adolescentes do Sexo Feminino
}

\author{
Indoor Soccer Practice in School: Reasons of Teenagers' Girls
}

Práctica de Fútbol Sala en la Escuela: Motivación de Adolescentes Mujeres

\author{
Ivens Suruagy Correia Moura $^{1}$ \\ Gustavo de Conti Teixeira Costa ${ }^{2}$ \\ Isis Suruagy Correia Moura ${ }^{3}$ \\ Luis Paulo de Souza Gomes ${ }^{4}$
}

\section{Resumo}

Objetivo: Verificar os motivos da prática do futsal na escola por adolescentes. Método: Trata-se de estudo qualitativo, realizado em Maceió, 2013, com 15 adolescentes, sexo feminino, que jogavam futsal como atividade de Educação Física. Usou-se como instrumento uma entrevista elaborada pelos pesquisadores e para a análise dos dados a teoria de Análise de Conteúdo. Resultados: Encontrou-se que o trabalho em equipe e a emoção que esporte proporciona foram razões principais de escolha da prática do Futsal e os principais sentimentos foram: sentir-se bem e feliz. O apoio dos pais e espírito grupal aparece como fatores favoráveis à prática do esporte e como dificuldades o cansaço relacionado ao preparo físico, a outras atividades do dia a dia. Os dados mostram que o trabalho em grupo na adolescência é importante e a prática do esporte é relevante para saúde mental. Conclusão: Os motivos que levam uma adolescente à praticar do futsal estão relacionados ao momento que vivenciam na adolescência, a influência sofrida pelas amigas na escolha do esporte e o trabalho em grupo. Visualiza-se com este estudo o fornecimento de subsídios para atuação docente.

${ }^{1}$ Professor de Educação Física. Especialista em Ciências do Esporte (UFGF). Autor correspondente: Av. Emp. Carlos da S. Nogueira. 16, apto 303, Jatiúca, Maceió, AL, Brasil. CEP: 57036540. E-mail: iscm@hotmail.com ${ }^{2}$ Professor Mestre da Faculdade Estácio de Sá. Doutorando em Ciências do Esporte (UFMG). ${ }^{3}$ Doutora em Neurociências (UFPE).

${ }^{4}$ Professor Mestre da Universidade Tiradentes (UNIT). 


\section{Palavras-chaves: Educação Física e}

Treinamento; Adolescente;

Motivação.

\section{Abstract}

Objective: to verify the reasons of indoor soccer practice in schools by teenagers. Method: This is a qualitative study that was carried out in Maceio, 2013, with 15 teenagers, women that played indoor soccer as their Physical Education activity. The instrument was an interview elaborately by researchers; for data analysis it was used the Content Analysis Theory. Results: There was found that team work and the emotion given by sport were the main reason for choosing indoor soccer and the main feelings were: to feel well and happy. The parents' support and team spirit arise as favorable factors to the sport's practice and as difficulty, fatigue from physical preparation and other daily activities. The data show that team work in adolescence is very important and that sports' practice is important to mental health. Conclusion: The reasons to practice futsal are related to the time they experience adolescence, the influence suffered by friends in the choice of sport and teamwork. This study can help teacher's actions.
Keywords: Physical Education and Training; Adolescent; Motivation.

\section{Resumen}

Objetivo: verificar las razones para la práctica del fútbol sala en la escuela para los adolescentes. Método: Se trata de un estudio de cualitativo, llevó a cabo en Maceió, 2013, 15 jóvenes, hembras, que jugaron fútbol sala como una actividad de educación física. Fue utilizada una entrevista desarrollada por los investigadores y la teoría de análisis de contenidos para análisis de los datos. Resultados: Se encontró que el trabajo en equipo y la emoción que el deporte ofrece fueron las principales razones de la elección de la práctica de fútbol sala y los principales sentimientos fueron sentirse bien y ser feliz. El apoyo de los padres y el espíritu de grupo aparece como factores favorables para la práctica de deportes; cómo dificultades la fatiga por causa de la falta de aptitud, junto a las otras actividades de la vida cotidiana. Los datos muestran que el trabajo en grupo en la adolescencia es importante y el deporte es relevante para la salud mental. Conclusión: Las razones que llevan a un adolescente 
para practicar fútbol sala están relacionados con las experiencias en la adolescencia, la influencia sufrida por los amigos en la elección del deporte y el trabajo en equipo. Se visualiza que este estudio puede servir de subvenciones para la enseñanza de la educación física.

Palabras clave: Educación y Entrenamiento Físico; Adolescente; Motivación.

\section{Introdução}

O esporte é um fenômeno milenar, que envolve vários aspectos: socioeconômicos, culturais e de saúde. No Brasil, desde cedo, o uso da bola se destaca. Na infância, as crianças já são influenciadas para gostar do futebol, recebendo bolas e uniformes de times como presentes dos adultos. Apesar disso, há diferenças de escolha do esporte em relação ao gênero, sendo as mulheres, às veze discriminadas em seu direito à prática de qualquer esporte, por suas características somáticas ${ }^{(1-3)}$.

A prática do esporte moderno, como atividade de educação física escolar no Brasil, manteve, por algum tempo, a mulher à parte de algumas atividades, por considerá-la portadora de um corpo frágil comparado ao do homem. Elas eram valorizadas em atividades como dança, ginástica rítmica e voleibol, por sua docilidade e sensibilidade, cabendo aos homens esportes e jogos mais agressivos que requerem esforço físico, confronto corpo a corpo e movimentos violentos como futebol, basquete e judô ${ }^{(1)}$.

A forma e o tamanho do corpo do atleta são tão importantes quanto o seu desempenho esportivo, quando se trata de esportes, particularmente em modalidades que exigem movimentação e agilidade do corpo, fato que leva a criação de conceitos sociais sobre esse desempenho e o corpo e sobre a valorização desse corpo. Estudos sobre a questão de gênero na Educação Física mostram questões culturais sobre a participação feminina nas aulas, apontando diferenças de atuação entre jogadores e jogadoras $^{(4,5)}$.

Uma das modalidades de esporte praticado como educação física escolar, no momento, no Brasil, é o futsal. Esse esporte teve maior evolução e reconhecimento durante os anos noventa do século passado, quando o Brasil passou a adotar as novas regras de jogo emanadas da Federação Internacional de Futebol (FIFA), tendo sempre como objetivos principais divulgar e desenvolver o Futsal desporto, bem como elevá-lo à 
modalidade integrada no programa dos Jogos Olímpicos ${ }^{(6)}$.

O futebol feminino começa a ser reconhecido no Brasil, quando é liberada sua prática em 1983, ocorrendo a legalização de sua prática que já existia mesmo sendo proibida. Com a criação dos Cursos Superiores de Educação Física, é possibilitado à mulher, o acesso às disciplinas relacionadas a esse esporte, e, consequentemente, a esse ambiente anteriormente masculino. Isso abre espaços para sua prática e para o seu ensino, que leva a estudos sobre gênero nessa área ${ }^{(7) .}$

O futsal é considerado uma modalidade brasileira de esportes e, em 2005, o futsal feminino é reconhecido no Brasil, passando a ser realizado um trabalho mais atento e apurado para as equipes femininas com a realização da Taça Brasil Principal. Essa modalidade consegue atingir vários níveis sociais da população e mesmo sendo uma modalidade competitiva, pode ser caracterizada como uma atividade recreativa e de lazer, cuja prática envolve diversos fatores motivacionais, entre eles: forma física, diversão, energia liberada e equipe ${ }^{(6,8-10)}$.

Atualmente a influência esportiva extrapola o gênero, aumentando a participação de adolescentes na prática do futsal, seja do sexo masculino ou feminino. $\mathrm{O}$ futsal surge como atividade que busca ocupação do tempo livre, de uma vida saudável ou até de uma futura profissão. É uma das modalidades esportivas mais praticadas no Brasil, estando em evidência nas práticas escolares, talvez por ser ativo, exigindo participação e cooperação entre participantes, permitindo enfrentar desafios, sentir-se útil junto aos amigos, aparecendo como forma de socialização ${ }^{(11)}$.

A motivação, que leva o jovem à prática de algum tipo de esporte, é resultado de vários fatores e atributos, que definem a escolha pela modalidade a ser praticada, bem como o envolvimento nos treinos e na busca de melhores rendimentos ${ }^{(12,13)}$. Assim, a prática de qualquer atividade física traz em seu bojo a motivação para sua busca, que estimula a iniciativa e determina o nível de entusiamo e esforço que uma pessoa usa no desenvolvimento de suas atividades. $\mathrm{O}$ nível de motivação é influenciado por diversos fatores como: a personalidade da pessoa, suas percepções do meio ambiente, interações humanas e suas emoções $^{(1)}$.

A adolescência, período entre os 10 e 19 anos de idade, apresenta transformações nos aspectos 
biopsicossociais. A mudança biológica, denominada puberdade, envolve alterações orgânicas, desenvolvimento dos caracteres sexuais secundários, ganho acelerado de estatura e peso ${ }^{(14)}$. As diferenças físicas e de gênero, levam às vezes a escolhas e práticas diferentes na vida; nos esportes como o futsal, o papel do homem é bastante conhecido, todavia alguns estudos publicados nos últimos anos mostram que a mulher vem ocupando espaços neste esporte $^{(1,13,15-16)}$.

Assim, este artigo pretende apresentar dados sobre o que leva uma adolescente do sexo feminino a escolher a prática do futsal e como se sentem praticando este esporte.

\section{Método}

Trata-se de um estudo de caso, qualitativo, realizado em uma amostra intencional, não probabilística no ano de 2013, em um colégio da rede particular da cidade de Maceió, Alagoas. Participaram do estudo 15 meninas, na faixa etária dos 13 aos 17 anos, alunas do Curso Fundamental e Médio que praticavam futsal como atividade de Educação Física. Os critérios de inclusão foram: ser adolescente, estar matriculada na escola selecionada e participar da equipe de futsal da referida escola; não houve critério de exclusão. Os Termos de Consentimento Livre e Esclarecido foram obtidos de todos os 15 pais/responsáveis e das próprias adolescentes, antes da entrevista individual.

Usou-se um roteiro de entrevista com perguntas abertas e fechadas, composto de três secções: aspectos sociodemográficos, aspectos motivacionais e aspectos físicos, que foi elaborado após revisão bibliográfica, pelos pesquisadores, tendo em vista a não disponibilidade do uso de um instrumento já validado sobre o tema futsal. Foram encontrados estudos e instrumentos sobre motivação para prática de esportes de uma forma geral.

As entrevistas individuais foram realizadas em uma sala de aula da escola selecionada, em um só momento, sendo anotadas as informações na hora da entrevista, contou-se com o auxílio da orientadora escolar, e a coleta foi realizada por um dos pesquisadores, que não tinha contato com as meninas para que não ocorressem interferências, tendo em vista que um dos pesquisadores era professor das alunas pesquisadas.

Para a análise dos dados obtidos nas questões fechadas, usou-se o Microsoft Excel@; nas questões abertas foi utilizada a teoria de Análise de 
Conteúdo, que se trata de "um conjunto de técnica de análise das comunicações que utiliza procedimentos sistemáticos e objetivos de descrição do conteúdo das mensagens"(17). Neste estudo foi considerando a análise de frequência do aparecimento das informações e seus aspectos temáticos.

Inicialmente foi realizada uma leitura rápida a fim de se apreender o conteúdo e as ideias gerais das entrevistas, sendo criada então uma planilha com as categorias principais, posteriormente foram realizadas várias leituras, para aprofundamento $\mathrm{e}$ apreensão dos significados e elaboração das categorias finais.

Assim, foi considerado o plano sincrônico (horizontal), para a análise descritiva do texto e um plano diacrônico (vertical), para as variáveis inferidas após a apreensão dos significados $^{(17)}$. Neste processo foram então identificadas as categorias do estudo: escolha e prática do Futsal como atividade de educação física, sentimentos, dificuldades e facilidades de adaptação ao esporte, apoio para a prática e modificações corporais.

Os dados apresentados são seguidos de nomes fictícios obedecendo-se ao critério do sigilo e da não identificação das adolescentes. A pesquisa foi realizada como trabalho de conclusão de curso de especialização, sendo aprovada pelo CEP da UFAL 11648812.0.0000.5013, parecer 176.866, em 11/01/2103.

\section{Resultados}

A amostra foi composta por 15 adolescentes na faixa etária dos 13 aos 17 anos de idade, alunas de uma escola de Maceió, matriculadas no ensino fundamental e médio, praticantes de Futsal como atividade de Educação Física, sendo a moda 14 anos e mediana de 15 anos.

As categorias escolha e prática do Futsal como atividade de educação física surgem em um contexto de trabalho em equipe, que é permeado pela emoção, que o esporte proporciona em sua prática. Assim, a razão mais frequente para participar do esporte como atividade de educação física neste estudo, foi a "influência das amigas", seguida pelo "amor ao esporte", e o destaque da jogadora alagoana Marta que aparece como "ídolo" das adolescentes pesquisadas.

\footnotetext{
“ Eu não gosto de fazer física, mas temos que fazer, aí, Catarina que estuda na mesma classe que eu e conhece outra menina de outra sala, soube que podíamos fazer esporte e resolvemos vim ver, como era, antes do nosso treino tem o
} 
treino dos meninos, (risos) daí pensei, eu vou fazer futsal" (Mariana, 15 anos).

"Adoro quando estou na quadra com minhas amigas, agente faz muitas coisas juntas, antes eu conhecia apenas a Luiza e a Mariana, depois ficamos todas amigas. Quando entro na quadra me esqueço do mundo" (Carla, 17 anos).

"Você sabe da Marta? Pois é, ela ó nosso ídolo, ou ídala? (risos) Deixa pra lá, pois é ela é o máximo, dá vontade de ser como ela" (Patrícia, 13 anos).

Todos os sentimentos identificados em relação ao esporte foram positivos e benéficos, quer seja na forma individual, como "alegria", "felicidade", "orgulho em participar da equipe", quer seja coletivamente pelo trabalho em grupo, na forma de "força e união de ganhar mesmo nos momentos mais difíceis". Destacaram-se, então, sentir-se bem, ficar feliz e sentir-se segura; o que corrobora o fato de apenas $26,8 \%$ delas afirmaram ter sentido dificuldades em se adaptar ao esporte na escola.

"É assim, tipo, eu amo fazer futsal, sou melhor nele do que no handebol, tenho segurança em correr atrás da bola (Mariana, 14 anos).

“ Sabe, eu não tenho dificuldade nenhuma no futsal, na quadra domino bem a bola e sou boa nos gols, tenho muita segurança, e me sinto super bem com minhas amigas do time (Josefa, 14 anos).
As dificuldades citadas para a prática do futsal feminino foram: dificuldades físicas, sendo o "cansaço" a razão principal, quer esteja relacionado ao preparo físico da atleta, quer esteja associado a outras atividades como o cursinho para o vestibular $(13,3 \%)$, dificuldade em dominar a bola $(6,7 \%)$ e dificuldade em acompanhar o ritmo das demais atletas $(13,4 \%)$.

"Tive muito cansaço quando comecei porque não tinha preparo, sabe, tipo, não fazia nada e daí começar a correr (risos), mas depois o professor me disse para vir todos os dias, sem faltar, participar dos treinos sem faltar e melhorei (Patrícia, 13 anos).

"Essa coisa do vestibular, cansa, quero estudar ate tarde, quero jogar, não perder a forma e puxa, fico cansada" (Carla, 17 anos).

A maioria das adolescentes expôs que seus pais apoiaram a escolha do esporte achando importante para o seu desenvolvimento integral. Contudo, uma pequena parcela $(26 \%)$ delas afirmou que a família não apoiou esta prática esportiva, afirmando que é um esporte para homem.

"Meus pais me apoiam muito, tipo, o que quero fazer que eles acham que é certo, daí fazer futsal, um esporte que tem um professor legal, que agente viaja com o colégio (Gabriela, 14 anos). 
"Meu irmão e meu pai dizem: isto é coisa de homem" (Fabíola, 15 anos).

"Minha mãe não diz nada, confia em mim, (risos) meu pai no começo achou ruim, isto é coisa de homem, você vai ficar musculosa, por que não vai para o ballet? (risos) Mas eu conversei, conversei e ele deixou" ( Rute, 15 anos).

"Gosto de praticar esporte, aprendi isto com minha família, e quando resolvi vir para esta escola e para o time, meu pai e minha mãe gostaram, porque eles gostam que eu pratique esporte, porque eles também fizeram isto quando eram jovens" (Fabiana, 15 anos).

O número de anos de prática do esporte variou de 1 a 9 anos, concentrando-se a maioria em três anos de sua prática. A maioria das jovens participantes da pesquisa não entendeu que o esporte provocou modificações em seu corpo e não se sentiram discriminadas pela sua escolha e prática. Aquelas que perceberam modificações corporais afirmaram que o corpo fica "mais forte", "preparado e com músculos" e "pernas bombadas".

As jovens que perceberam a discriminação quanto à pratica do esporte atribuíram este fato à discriminação sentida e relacionada com questão de gênero, afirmando que as pessoas dizem que é um esporte de homem. As pessoas que discriminaram foram os próprios colegas do sexo masculino, pais e mães, sejam delas próprias, sejam das amigas que não praticam o esporte.

“[...] eu não, mas minha amiga que joga aqui brigou com o namorado, porque ele disse que ela ia ficar Maria-João, que ele não queria namorar uma menina que jogava futebol (Amália, 16 anos).

“[...] fui u dia na casa da minha amiga e a mãe dela disse, Patrícia, cuidado, você vai ficar feia jogando futebol. Tive uma raiva, daí sai e nem falei com minha amiga ( Patrícia, 13 anos).

\section{Discussão}

A adolescência se caracteriza pela importância do grupo na vida do jovem, momento em que a opinião dos pares começa a ocupar o lugar que era dedicado aos pais. Tal fato é visualizado na afirmativa da escolha do futsal como esporte e atividade física que informa a influência das amigas como a mais frequente. Neste momento o jovem escolhe figuras de destaque para substituir o amor parental e neste caso encontramos neste estudo a figura da jogadora de futebol alagoana, Marta, citada como ídolo de futebol ${ }^{(12,18)}$.

Um estudo ${ }^{(8)}$ encontrou que as razões para a prática do futsal era o sentimento de participar de uma equipe 
e a diversão, resultados que são semelhantes aos deste estudo. Destacamos neste estudo a escolha do futsal como atividade física, influência das amigas e da jogadora Marta para sua prática e amor ao esporte, explica-se que Marta Vieira da Silva foi eleita por três anos a melhor jogadora do mundo e ganhou medalhas de ouro nos jogos Pan Americanos de 2003 e 2007.

Souza $^{(1)}$ encontrou resultados semelhantes aos deste estudo em relação às razões para a prática do esporte, como possibilitar o esquecimento dos problemas, reunir-se com amigos e fazer uma atividade física.

Apesar da relevância do papel do grupo na faixa etária aqui estudada, os pais continuam sendo importantes para suas filhas nesse estágio de vida ${ }^{(12)}$. Verificou-se neste estudo que, em relação ao apoio para esta prática esportiva, os pais foram importantes na opinião das jovens, com sua presença e estímulo, fato que se revela nas afirmativas das jovens que se sentiam apoiadas pelos pais na escolha deste esporte.

Algumas afirmaram que os pais achavam "importante a prática do futsal para o seu desenvolvimento" o que destaca o papel e a importância do esporte como um todo para o desenvolvimento do ser humano. Souza $^{(1)}$ também identificou a importância do apoio dos pais às atletas em seu estudo.

Os dados aqui encontrados também podem ser discutidos, considerando-se o fato de que futsal vem se tornando um esporte diferenciado, em relação ao rendimento, plano tático, regras e parte técnica. As crianças têm sido direcionadas a sua prática por sua similaridade de desenvolvimento com o futebol, considerando-se que ambos são jogados com os pés. $\mathrm{O}$ ato de ser praticado precocemente permite $\mathrm{o}$ desenvolvimento de performances esportivas bem refinadas, que exigem dedicação intensa. Pais interessados em que seus filhos se tornem exímios jogadores de futebol no futuro incentivam-nos na prática do futsal inicialmente $^{(3)}$.

As jovens também relataram a discriminação deste esporte para mulheres, por alguns conhecidos, o que pode ser relacionado à questão de gênero. Algumas informaram "que as pessoas dizem que é um esporte de homem". Assim, esta questão de gênero aparece nos resultados desta pesquisa quando se observa a fala das jovens cujos pais não estimularam a prática do esporte afirmando que é um "esporte 
para homem", quando a mãe e o namorado da amiga criticaram sua prática.

Estes resultados são corroborados pelo estudo de Souza ${ }^{(1)}$ que encontrou afirmações como: "me chamam de doida", "dizem que mulher não pode jogar futebol". Observa-se que a discriminação quanto à prática do esporte está relacionada ao gênero, refletindo a cultura de uma sociedade machista onde se diz que é um esporte de homem mostrando o pensamento do início e da criação do esporte ${ }^{(7,19)}$.

Adelman $^{(20)}$ traz em seu estudo que a fala das atletas pesquisadas "sugere algumas formas em que a prática esportiva se constrói como um campo de definição e redefinições de significados sobre o corpo feminino" informando que há contextos e fatores sociais que influenciam na prática esportiva feminina. $\mathrm{O}$ que é visto nos resultados deste estudo quando as jovens não abrem mão da sua escolha mesmo diante das recriminações de algumas pessoas, e quando informam que o esporte deixa seus "corpos sarados".

A adolescência é a fase de desenvolvimento humano que traz grandes transformações principalmente no que se refere à sexualidade $\mathrm{e}$ formação de identidade. Outro fator relatado para a prática do esporte que chama a atenção para a fase de desenvolvimento das jovens foi a citação de que garotos bonitos estavam praticando o esporte, isto parece ser uma atração que se coaduna com a fase de desenvolvimento na qual as jovens estão inseridas ${ }^{(18,21)}$.

Nos séculos passados, o corpo da mulher era observado segundo a sua função e missão reprodutiva, sendo valorizados atributos como elegância e delicadeza, limitando as práticas físicas àquelas que concordavam com $\mathrm{o}$ pensamento da fragilidade do corpo feminino. Assim, no Brasil, até 1975, colocava-se legalmente que não era permitida às mulheres a prática de desportos incompatíveis com as condições da sua natureza. $\mathrm{Na}$ atualidade, o mundo esportivo tem, em parte, incorporado a luta das mulheres para se apropriarem de espaços existentes e/ou para criar novos ${ }^{(20)}$.

Quando indagadas sobre a prática do esporte e o corpo, a maioria afirmou que não via modificação no seu corpo pela prática do esporte a não ser aquelas relacionadas a um corpo atlético. Tal fato mostra que os tabus relacionados a futebol como esporte masculino ou masculinizante não são percebidos pelas atletas nem sentindo em sua forma física feminina ${ }^{(11,21)}$. 
Têm sido observados danos físicos e psicológicos em atletas de alto nível, como consequências das pressões sofridas na prática desportiva. $\mathrm{O}$ excesso nos limites de sua capacidade física e psicológica traz ansiedades ${ }^{(16)}$. Não foram encontrados na revisão de literatura artigos que estudassem especificamente emoções/sentimentos de adolescentes do sexo feminino na prática do futsal como esporte e atividade de educação física, o que prejudicou a discussão, neste estudo.

$$
\text { Aqui foram citados }
$$

sentimentos "benéficos", tais como a "emoção da alegria", a força do grupo pela "união para vencer os jogos nos momentos mais difíceis" o que possibilita afirmar que tais sentimentos podem demonstrar a importância da participação das adolescentes no futsal para sua saúde mental e desenvolvimento emocional ${ }^{(10,21)}$.

\section{Conclusão}

Os dados encontrados mostram que os motivos que levam uma adolescente a praticar o futsal como atividade física estão relacionados ao momento que vivenciam na adolescência, não somente com a influência sofrida pelas amigas na escolha do esporte bem como a importância do trabalho em grupo, fato que acontece na prática de esportes coletivos como o Futsal. O fortalecimento de fatos como este pode favorecer a uma vida saudável, colocando os jovens frente a escolhas benéficas ao seu desenvolvimento social, físico e mental.

O aparecimento da jogadora alagoana Marta, como ídolo e modelo para o aprendizado e exercício do esporte, demonstra a importância das figuras de identificação que os jovens escolhem neste momento de desenvolvimento, figuras que podem contribuir ou não para um caminho salutar.

Os sentimentos citados pelas jovens em relação ao esporte estudado demonstram a importância da participação das adolescentes na busca da saúde física e mental. Visualiza-se neste estudo a possibilidade de benefícios quanto à melhora do desempenho das atletas, ao apoio quanto a conflitos identificados nas respostas das adolescentes, bem como o fornecimento de subsídios para uma melhor atuação dos docentes da modalidade do esporte aqui abordado.

A parca literatura publicada, relacionada aos objetivos aqui pesquisados limitaram a discussão e comparação dos dados. Reconhece-se a 
limitação deste estudo e sugere-se a realização de novas investigações que venham subsidiar a prática do futsal feminino.

Os autores informam que não houve conflito de interesses na realização deste estudo.

\section{Referências}

1. Souza MM. Futsal também é coisa de mulher: por que será que elas o praticam? 2011. 33 f. Trabalho de Conclusão de Curso (Graduação). Escola de Educação Física Universidade Federal do Rio Grande do Sul. Porto Alegre, 2011.

2. Paes RRA. A pedagogia do esporte e os jogos coletivos. In: Rose D. Esporte e atividade física na adolescência: uma abordagem multidisciplinar. Porto Alegre: Artmed, 2002.

3. Cavichiolli FRC, Chinhak AB, Capraro AM, Marchi Júnior W., Mezzadri FM. O processo de formação do atleta de futsal e futebol: análise etnográfica. Revista brasileira de educação física e esporte. 2011; 25(4):631-47.

4. Hillebrand M D, Grossi PK, Moraes, JF. Preconceito de gênero em mulheres praticantes do esporte universitário. Psicologia. 2008; 39 (4): 425-30.

5. Brito LT, Santos MP. Masculinidades na Educação Física escolar: um estudo sobre os processos de inclusão/exclusão. Revista brasileira de educação física e esporte. 2013; 27 (2): 235-46.
6. Soares D, Oliveira C, Carneiro A. A motivação para o futsal em atletas participantes dos Jogos do Interior de Minas-JIMI. Revista Digital de Buenos Aires 2010; 15(48).

7. Votre S. A Representação da mulher na Educação Física e no esporte. Rio de janeiro: Editora Central da Universidade Gama Filho, 1996.

8. Scotá TC, Reis LFCM. Aspectos motivacionais no futsal feminino de Porto Alegre. Revista Técnico Científica.2012;3 (1):291-9.

9. Leite MRM, Santos M. Motivações de alunos do Ensino Técnico Integrado para a prática do Futsal no IFCE. Anais do VI Congresso de Pesquisa e Inovação da Rede Norte e Nordeste de Educação Tecnológica. Natal- RN, 2011.

10. Rohlfs ICP, Carvalho TMC, Rotta TM. Aplicação de instrumentos de avaliação de estados de humor na detecção da síndrome do excesso de treinamento. Revista Brasileira de Medicina do Esporte. 2004;10(2): 1116.

11. Gomes AR, Pereira AP, Pinheiro AR. Liderança, coesão e satisfação em equipas desportivas: um estudo com atletas Portugueses de futebol e futsal. Psicologia Reflexão e Critica. 2008;21(3):482-91.

12. Guedes DP, Silverio Netto JE. Motivos para a prática de esportes em atletas jovens e fatores associados. Revista de educação física/UEM. 2013;24(1):21-31.

13. Guedes DP. Níveis de prática de atividade física habitual em adolescentes. Revista Brasileira de Medicina do Esporte.2001;7(6):187-99. 
14. Correia DS. Adolescentes no Trânsito: perigo à vista? Maceió: Catavento. 2000.

15. Souza OM, Darido SC. A Prática do Futebol Feminino no Ensino Fundamental. Motriz. 2002;8(1):1-9.

16. Silva CC. O exercício físico potencializa ou compromete $\mathrm{O}$ crescimento longitudinal de crianças e adolescentes? Mito ou verdade? Revista Brasileira de Medicina do Esporte. 2004;10(6):520-4.

17. Bardin L. Análise de Conteúdo. São Paulo: Ed. 70. 2001.

18. Bee HÁ. Criança em Desenvolvimento. $11^{\mathrm{a}}$ Ed. Porto Alegre: Artes Médicas, 2011.

19. Magalhães S. Memórias, Futebol e Mulher: anonimato, oficialização e seus reflexos na Capital Paraense. Revista de História de Esporte. 2008;1(2):1-39.

20. Adelman M. Mulheres atletas: resignificações da corporalidade feminina. Revista Estudos Feministas. 2003; 11(2): 445-65.

21. Mackelvie KJ, Khan KM, Mickay HA. Is there a critical period for bone response to weight-bearing exercise in children and adolescents? A systematic review. British Journal of Sports Medicine. 2002; 36(1):250-7. 